\title{
Basophil Production
}

\author{
Judah A. Denburg, Maureen Davison, and John Bienenstock, \\ Host Resistance Programme, Departments of Medicine and Pathology, \\ McMaster University, Hamilton, Ontario, Canada, L8S $4 \mathrm{~J} 9$
}

A B S T RACT Factors influencing basophil production from the bone marrow of ovalbumin (OA)sensitized guinea pigs have been examined in vitro. Autologous co-cultures of marrow and spleen cells from OA-immune animals contained significantly higher numbers of basophils after $7 \mathrm{~d}$ of liquid culture in the presence of $\mathrm{OA}$, compared with control co-cultures or with marrow cultures alone $(P<0.005)$.

Basophils increased in co-culture as the number of spleen cells added to a fixed number of marrow cells was increased from 0.10 to $2.5 \times 10^{6} / \mathrm{ml}$; at each spleen cell concentration, the presence of $O A$ significantly enhanced basophil production in vitro when compared with unstimulated co-cultures. There was no basophil production from spleen cell suspensions cultured in the absence of autologous marrow cells. Conditioned media (CM) prepared from OA-stimulated spleen cells of OA-treated animals (CM-OA) caused a specific stimulation of basophil production from normal guinea pig bone marrow cells in liquid cultures $(P<0.01)$. Phytohemagglutinin (PHA)- and pokeweed mitogen-stimulated CM (CM-PHA, CMpokeweed mitogen) nonspecifically enhanced normal basophilopoiesis, causing dose-dependent increases in basophils and histamine in vitro. CM-OA and CMPHA also preferentially stimulated formation of neutrophil-macrophage colony-forming units in semisolid methylcellulose cultures.

CM-PHA prepared from $T$ cell-enriched splenic cell suspensions contained basophil-stimulating activity, whereas $\mathrm{T}$ cell-depleted CM-PHA activity did not exceed control values $(P<0.01)$. Preliminary characterization of CM-PHA revealed that basophil-stimulating activity was predominantly heat stable and nondialyzable.

These results demonstrate OA-specific, as well as mitogen-dependent $\mathrm{T}$-cell regulation of guinea pig basophilopoiesis in vitro. The data are compatible with the existence of a specific "basophilopoietin" in $\mathrm{CM}$ derived from guinea pig splenic $\mathrm{T}$ cells.

Received for publication 15 May 1979 and in revised form 8 September 1979.

\section{INTRODUCTION}

Lymphomononuclear cell-derived factors that stimulate the in vitro differentiation of bone marrow precursor cells are well recognized. Colony-stimulating activity (CSA) ${ }^{1}$ derived from lymphocytes for human or murine neutrophil (1), monocyte-macrophage (2), eosinophil (3), megakaryocyte (4), and lymphoid (5) cell lines has been described. CSA with crossspecies activity produced by mitogen-stimulated human monocytes and lymphocytes has now been characterized (6), and T cells that enhance erythropoiesis in semisolid media have recently been reported (7).

There is no similar information, however, about the factors necessary for the growth and differentiation of basophils. Despite the marked increase in this cell type in the peripheral blood in some of the human myeloproliferative disorders, there is only one recent study suggesting an increased capacity for basophilopoiesis in long term liquid cultures of buffy coat cells from patients with chronic myeloid leukemia (8).

Metcalf and his co-workers $(9,10)$ have begun to describe the morphology of human granulocyte colonies grown in semisolid media, demonstrating that $\sim 3 \%$ of these colonies are comprised of pure eosinophils, and that eosinophil colony formation can be enhanced by human placental lactogen or lymphocyte-conditioned media. This suggests that committed marrow precursor cells exist for each of the specialized granulocytic types described. More recently, a specific eosinophil colony-stimulating factor has been partially separated by isoelectric focusing of pokeweed mitogen (PWM)-stimulated splenic lymphocyte-conditioned media (11).

Little evidence exists for a committed basophil precursor either in semisolid or liquid culture, al-

\footnotetext{
${ }^{1}$ Abbreviations used in this paper: BSI, basophil stimulation index; CFU-C, colony-forming units in culture; CM, conditioned medium; CSA, colony-stimulating activity; HSA, human serum albumin; OA, ovalbumin; PHA, phytohemagglutinin; PWM, pokeweed mitogen; RSA, rabbit serum albumin.
} 
though human bone marrow colony-forming cells in culture (CFU-C) have been reported to give rise to small numbers of basophils in liquid culture (12).

The model of Basten and Beeson (13) for eosinophilia in Trichinella-infected mice clearly implicates $\mathrm{T}$ lymphocytes to be necessary for eosinophil production. In both murine and human systems, antigenand mitogen-dependent lymphocyte-derived stimulators of eosinophilopoiesis have now been described (14-17). Furthermore, eosinophilia may be closely related to T-cell factors (14), which also have been postulated to be secreted in the course of an eosinophilic-delayed hypersensitivity response in mice (18). The control of basophil homeostasis with specific reference to the immune response is much less clear. Injected tumor cell extracts from rats with basophilic leukemia were shown to cause increases in normal rat marrow basophil counts, but the mechanism of this response was not sought (19).

Dvorak et al. (20) have developed models of cutaneous and systemic basophilia in the guinea pig, and it has been demonstrated that some basophil hypersensitivity responses require the participation of both $\mathrm{T}$ cells and specific antibodies (21).

Previous work from this laboratory has demonstrated a thymic antigen to be present on rabbit basophils (22), suggesting that $\mathrm{T}$ lymphocytes and basophils are related in ontogeny. This concept has found further support in a recent study showing a functional relationship between basophils and the thymus (23). We have used a modified protocol (20) of large amounts of intraperitoneal ovalbumin (OA) to induce basophilia in vivo to study in vitro basophil production in the guinea pig. Our initial investigations of guinea pig basophilopoiesis demonstrate requirements for OA antigen, splenic T lymphocytes, and mitogen-dependent soluble $\mathrm{T}$-cell products in the differentiation of marrow precursors to basophils.

\section{METHODS}

Animals. Random bred, colored-hair guinea pigs (High Oak Farms, Goderich, Ontario, Canada), weighing 250-500 g, were used throughout.

Stimulation and estimation of peripheral blood and bone marrow basophilia in vivo. Animals were given 1-ml intraperitoneal injections of lyophilized OA, grade III (Grand Island Biological Co., Grand Island, N. Y.), dissolved in $0.9 \%$ of $\mathrm{NaCl}$ at $50 \mathrm{mg} / \mathrm{ml}$, or $1 \mathrm{ml}$ of $0.9 \% \mathrm{NaCl}$ by the same route, for 6 successive d, based on a protocol for promotion of basophilia developed by Dvorak et al. (20). Peripheral blood was obtained by serial $0.5-1.0-\mathrm{ml}$ cardiac bleeds, and femoral bone marrow aspirations $(0.1-0.25 \mathrm{ml})$ performed in the same animals via a pediatric 19-gauge Osgood biopsy needle (Becton, Dickinson \& Co., Rutherford, N. J.) under ketamine anesthesia. Blood and bone marrow nucleated cell counts using the Coulter $\mathrm{Zb}$ (Coulter Electronics, Inc., Hialeah, Fla.) were performed serially in each guinea pig (which thus served as its own control) before and during the course of intraperitoneal injections, as well as up to $120 \mathrm{~d}$ after completion of treatments in some animals. All samples were taken into $2 \mathrm{mg} / \mathrm{ml}$ EDTA (disodium salt, Matheson, Coleman \& Bell, East Rutherford, N. J.) under sterile conditions. Peripheral blood and bone marrow smears were made, air-dried, and stained with May-GrünwaldGiemsa (Harleco, Hartman-Leddon, Philadelphia, Pa.) or $0.05 \%$ toluidine blue-0 (Fisher Scientific Co., Pittsburgh, $\mathrm{Pa}$.) and 500-1,000 cell-differential counts were performed. Smears of single cell suspensions of bone marrow prepared for culture (see below) were made by cytocentrifuge and stained similarly for differential counts. Absolute basophil counts were calculated from the total viable nucleated cell counts and the differential percentage of basophils on smears.

The usual range of basophils counted was 0.1 to $3.0 \%$ of peripheral blood or bone marrow nucleated cells (1-30 in a 1,000-cell differential). Highest values were seen in bone marrow cell suspensions of OA-treated animals. Counts were reliable and reproducible; histamine values, used as an independent criterion of basophilia, correlated well with calculated differential basophil counts (see below). Attempts at accurate assessment of absolute basophils by direct live staining with toluidine blue were not routinely successful, even when guinea pig serum was used (20).

\section{Preparation of bone marrow and spleen cell cultures}

Bone marrow, liquid cultures. Guinea pig bone marrow cell suspensions from untreated, saline-, or OA-treated animals were prepared either from samples aspirated directly from femora (see below) or from the contents of femora and tibiae freed of muscle and tendon attachments, cut at both ends, and flushed with sterile McCoy's 5A medium, with $15 \%$ fetal calf serum, and $1 \%$ penicillin-streptomycin (all from Grand Island Biological Co.). After resuspension, cell debris was removed by sedimentation at unit gravity and then at $400 \mathrm{~g}$ over $100 \%$ fetal calf serum, after methods described by Shortman et al. (24). Single marrow cell suspensions in medium were placed over a Ficoll-Hypaque (Ficoll-400, Pharmacia Fine Chemicals, Inc., Div. Pharmacia, Inc., Uppsala, Sweden; Hypaque-sodium, 50\%, Winthrop Laboratories, New York), density gradient (specific gravity $=1.085$, $311 \mathrm{mosmol} / \mathrm{kg}$ ) at a cell concentration of $10-20 \times 10^{6} / \mathrm{ml}$ and centrifuged at room temperature for $40 \mathrm{~min}$ at $400 \mathrm{~g}$. Interface cells were removed, resuspended in medium, washed three times and single cell suspensions made at 1 $\times 10^{6} / \mathrm{ml}$ in the same medium. $5 \mathrm{ml}$ of these suspensions was placed in Falcon $25-\mathrm{cm}^{2}$ plastic flasks (Falcon Labware, Div. of Becton, Dickinson \& Co., Oxnard, Calif.), with or without co-cultured spleen cells, conditioned medium (CM) supplementation at $1-20 \% \mathrm{vol} / \mathrm{vol}$, OA, or human (HSA, Fraction V, from Pentex Biochemical, Kankakee, Ill., Miles Laboratories, Inc., Montreal) or rabbit-serum albumin (RSA, Fraction V, Nutritional Biochemicals Corp., Cleveland, Ohio) at $10 \mu \mathrm{g} / \mathrm{ml}$. All cultures were further supplemented with 2-mercaptoethanol (Sigma Chemical Co., St. Louis, Mo.) at $50 \mu \mathrm{m}$ final concentration. Cells were cultured at $37^{\circ} \mathrm{C}$ and $5 \% \mathrm{CO}_{2}$ in a moist incubator and harvested at $7 \mathrm{~d}$; cytocentrifuge smears and stains, 1,000 cell-differential counts, and cell-associated histamine assays were performed on all cell suspensions.

Bone marrow, methylcellulose cultures. Semisolid cultures of $1-2 \times 10^{5}$ cells $/ 35 \times 10 \mathrm{~mm}$ Falcon tissue culture Petri dish in Dow A4M Premium methylcellulose $(2.2 \%$; Dow Chemical Co., Midland, Mich.) supplemented with $20 \%$ fetal calf serum and $20 \% \mathrm{vol} / \mathrm{vol}$ medium/2-mercapto- 
ethanol or CM/2-mercaptoethanol (diluted to appropriate final concentration) were performed by techniques previously described $(4,7,9)$. CFU-C were counted on day 7 by inverted microscope in duplicate or quadruplicate for each condition. CSA was defined as the ability to stimulate CFU-C in methylcellulose cultures. Individual colonies were picked by a 5 - $\mu$ l micropipette under microscopy and diluted in three drops McCoy's 5A medium before preparation of cytocentrifuge smears. These smears were stained and counted as above.

Spleen. Spleen cell suspensions were prepared by removing spleens intact under sterile conditions into medium, teasing with wooden applicator sticks, and using the procedures of Shortman et al. (24) for removal of fine and coarse cellular debris. To remove contaminating erythrocytes, cells were exposed to $0.17 \mathrm{M} \mathrm{NH} \mathrm{NH}_{4} \mathrm{Cl} 4^{\circ} \mathrm{C}$ for $10 \mathrm{~min}$. Cell suspensions so obtained were washed three times, resuspended at $1 \times 10^{6 / \mathrm{ml}}$, and cultured as above or co-cultured with marrow cells. Spleen cell basophil counts ranged from 0.05 to $0.2 \%$; $\geq 90 \%$ of spleen cells were lymphomononuclear. Cell viabilities were assessed by Trypan blue (Harleco Hartman-Leddon), dye exclusion, and were always $>9.5 \%$ for freshly prepared marrow or spleen suspensions.

Preparation and assay of spleen cell C.M. Spleens were removed from animals sacrificed $2-4$ mo after treatment with either OA or saline. Single splenic cell suspensions at $\mathrm{I} \times 10^{6} / \mathrm{ml}$, with or without $10 \mu \mathrm{g} / \mathrm{ml}$ OA, HSA, RSA, phytohemagglutinin (PHA-M); (Difco Laboratories, Detroit, Mich.), or $0.1 \%$ PWM (Grand Island Biological Co.) were prepared as described and cultured at $37^{\circ} \mathrm{C}$ and $5 \% \mathrm{CO}_{2}$ in $100 \%$ humidity for $5 \mathrm{~d}$. Cell-free supernates obtained from these cultures were filtered throngh $0.22-\mu \mathrm{m}$ Millipore filters (Millipore Corp., Bedford, Mass.) and stored at $-20^{\circ} \mathrm{C}$ for up to $14 \mathrm{mo}$; these $\mathrm{C.M}$ were assayed at $1-20 \% \mathrm{vol} / \mathrm{vol}$ in liquid and in methylcellulose cultures using normal, previously untreated, guinea pig marrow cells as targets in both systems.

A "basophil stimulation index" (BSI) of C.M in liquid cultures was calculated by the following ratio: $\Delta$ basophils (from day 0 ) in presence of C.M: $\Delta$ basophils (from day 0) in absence of C.M.

Histamine assay. Cell-associated histamine assays were performed on all cell suspensions by a modification of the method described by Beaven (25). The technique used is based on the conversion of histamine to $\left[{ }^{3} \mathrm{H}\right]$ methylhistamine by incubation with histamine $N$-methyltransferase and [methyl $\left.-{ }^{3} \mathrm{H}\right]-\mathrm{S}$-adenosylmethionine.

Smlenir T-cell separation. Splenic T cells were separated by their ability to form rosettes with rabbit erythrocytes, according to methods described by Wilson and Gurner (26). Briefly, $5 \mathrm{ml}$ of a $3 \%$ suspension of papainized, sterile washed rabbit erythrocytes was mixed with an equal volume of a twice-washed splenic cell suspension at $1.8 \times 10^{7}$ cells/ml. After a $5-\mathrm{min}$ centrifugation at $100 \mathrm{~g}$, the pellet was incubated for $1 \mathrm{~h}$ at room temperature. The pellet was gently resuspended, layered onto a Ficoll-Hypaque density gradient (see above), and centrifiged for $30 \mathrm{~min}$ at $400 \mathrm{~g}$. Interface cells (T-depleted) were removed and washed twice in $1 \%$ bovine serum albumin in phosphate-buffered saline while the pelleted (T-enriched) cells were subjected to hypotonic lysis for $30 \mathrm{~s}$ and washed twice in the same way. E-rosettes were enumerated in a hemocrtometer, using $0.1 \%$ toluidine blue; 200 cells were counted and only cells with three or more bound erythrocytes were deemed "E-positive" (T cells). Cells from each fraction were then incubated with a fluorescinated goat anti-guinea pig immunoglobulin (Ig)G (whole) and counted for surface immunoglobulin positivity. Percentages of IgG-positive cells were thus obtained for each spleen cell fraction.

Morphology. A cell was morphologically defined by light microscopy as a basophil if there was nuclear indentation or polymorphonuclearity, if it contained granules that stained metachromatically, and if the granules themselves appeared ovoid, considered a characteristic of guinea pig-specific granulation. Other cells were classified by accepted hematological criteria. Mast cells are very rarely, if at all, encountered in the guinea pig; they were not seen in our peripheral blood, spleen, or bone marrow cultures. When seen by others, guinea pig mast cells have been distinguishable from basophils by size, location in and difficult extraction from connective tissues. mononuclearity, and a partially vacuolated gramule-containing (ytoplasm (27).

\section{RESULTS}

Peripheral blood and bone marrow basophil responses in vivo. The serial peripheral blood basophil response to 6 successive $d$ of intraperitoneal injections in 24 guinea pigs is shown in Table I. Basophil counts increased by a mean of approximately fivefold in 15 OA-treated animals when compared with nine saline-treated controls. Increased numbers of circulating basophils were seen by day 3 of injections, remained significantly elevated at day 7 ( $1 \mathrm{~d}$ after cessation of injections), and subsided within $10 \mathrm{~d}$ after withdrawal of OA; day 14 counts in OA-treated animals were not significantly different from untreated control values. Serial total leukocyte counts did not differ among animal groups (OA, saline, or untreated) when

TABLE I

Peripheral Blood Response to 6 Successite d of Intraperitoneal OA in the Guinea Pig

\begin{tabular}{|c|c|c|c|c|c|c|c|}
\hline \multirow[b]{2}{*}{ Group } & \multirow{2}{*}{$\begin{array}{l}\text { Untreated } \\
\text { normal }\end{array}$} & \multicolumn{6}{|c|}{ Treated } \\
\hline & & & Saline & & & $\mathrm{OA}$ & \\
\hline Day of injections & 0 & 0 & 3 & 7 & 0 & 3 & 7 \\
\hline Total nucleated cells & $8.89 \pm 0.964$ & $8.36 \pm 2.79$ & $8.86 \pm 1.25$ & $9.12 \pm 1.45$ & $9.21 \pm 1.06$ & $9.45 \pm 1.12$ & $10.6 \pm 2.42$ \\
\hline Basophils & $\begin{array}{c}34.9 \pm 3.9 \\
(24)\end{array}$ & $\begin{array}{c}36.2 \pm 4.1 \\
(9)\end{array}$ & $\begin{array}{c}48.2 \pm 6.0 \\
(9)\end{array}$ & $\begin{array}{c}38.5 \pm 7.1 \\
(7)\end{array}$ & $\begin{array}{c}33.6 \pm 2.9 \\
\text { (15) }\end{array}$ & $\begin{array}{c}177 \pm 31.9 \\
(14)\end{array}$ & $\begin{array}{c}123 \pm 35.2 \\
(8)\end{array}$ \\
\hline
\end{tabular}

Mean total nucleated cells $\times 10^{3} / \mathrm{mm}^{3} \pm$ SE. Mean absolute basophils per $\mathrm{mm}^{3} \pm \mathrm{SE}$. Numbers per group in parentheses. Day 3 and 7 OA-treated group basophils differ significantly from day 3 and day 7 saline-treated group basophils, respectively, and from normal values, $P<0.05$. No significant differences in total nucleated cell counts between subgroups or days. 
assessed during the course of induction of basophil responses in vivo (Table I). Eosinophils appeared to rise transiently in some animals during the injection protocol with OA, and up to $1 \mathrm{wk}$ after injections. This rise was neither consistent nor statistically significant when compared with the saline treatment group. Bone marrow counts rose significantly at $7 \mathrm{~d}$ in OA-treated animals when compared with 12 untreated or 9 salinetreated controls (Table II). Of interest was the finding that the marrow basophil response subsided totally within 2 mo of $\mathrm{OA}$ injections in six animals checked serially over this time-course (Table II). Cells from these animals were then set up in autologous marrow-spleen co-cultures for investigation of "secondary" basophil responses in vitro (see below) and for preparation of CM (see Methods).

Autologous marrow-spleen co-cultures: secondary basophil response in vitro. The effect of in vitro exposure to $\mathrm{OA}$ of marrow and spleen cells from previously OA-treated guinea pigs is shown in Table IIIA. Autologous 1:1 marrow-spleen co-cultures, using 0.5 $\times 10^{6}$ cells $/ \mathrm{cm}^{3}$ of each, were carried out in liquid culture with or without $10 \mu \mathrm{g} / \mathrm{ml}$ of OA, HSA, or RSA over a 7-d period. Increased numbers of basophils were observed specifically in the presence of OA when compared with unstimulated or control co-cultures. A slight but statistically insignificant increase in basophils ascribable to the presence of OA could be demonstrated for marrow cells from OA-treated animals when cultured without autologous spleen cells (see below).

Table IIIB shows the results of marrow-spleen liquid co-cultures at $7 \mathrm{~d}$ when spleen cells added to a fixed marrow cell number $\left(0.5 \times 10^{6} / \mathrm{cm}\right)^{3}$ in the presence or absence of OA. Through a range of spleen cells added $\left(0.5-2.5 \times 10^{6} / \mathrm{cm}^{3}\right)$, OA-stimulated cultures consistently demonstrated higher numbers of basophils when compared with unstimulated cocultures. Variability in absolute intensity of the basophil response to $\mathrm{OA}$ in vitro was apparent from ex-

TABLE II

Bone Marrow Basophil Response to Intraperitoneal $\mathrm{OA}$ in the Guinea Pig

\begin{tabular}{lcc}
\hline \multicolumn{1}{c}{ Treatment } & Day of treatment* & Basophils $\times 10^{3} / \mathrm{cm}^{3}$ \\
\hline None $(n=12)$ & 0 & $5.8 \pm 1.1$ \\
Saline-treated $(n=9)$ & 7 & $7.9 \pm 1.1$ \\
OA-treated $(n=11)$ & 7 & $25.9 \pm 7.4 \ddagger$ \\
OA-treated $(n=6)$ & 60 & $7.1 \pm 1.2$ \\
\hline
\end{tabular}

Mean \pm SE

* 6 successive $\mathrm{d}$ of intraperitoneal OA or saline on days 1-6 only.

† Day 7 OA-treated group values differ significantly from untreated, day 7 saline-treated, or day 60 OA-treated, $P<0.05$.
TABLE IIIA

Basophil Response in vitro: Effect of Specific Antigen on Basophilopoiesis from Separated Marrow Cells Cultured Alone or with Added Autologous Spleen Cells $60 \mathrm{~d}$ after Primary Exposure

\begin{tabular}{llcc}
\hline & & \multicolumn{2}{c}{ Day of culture } \\
\cline { 3 - 4 } Condition & $\begin{array}{c}\text { Stimulus } \\
\text { in vitro }\end{array}$ & 0 & 7 \\
\hline Marrow alone & None & $2.5 \pm 0.8$ & $13.6 \pm 3.0$ \\
& OA & & $17.0 \pm 6.0$ \\
& HSA & & $10.6 \pm 0.3$ \\
& RSA & & $9.6 \pm 2.0$ \\
Marrow: spleen (1:1) & None & $3.3 \pm 0.7$ & $14.5 \pm 5.0(a)$ \\
& OA & & $31.1 \pm 6.0(b)$ \\
& HSA & & $10.9 \pm 3.5$ \\
& RSA & & $15.3 \pm 2.0$ \\
Spleen alone* & None & $<0.5$ & $<0.5$ \\
& OA & $<0.5$ & $<0.5$ \\
\hline
\end{tabular}

Mean absolute basophils $\times 10^{3} \pm$ SE. Results of eight experiments in duplicate. Day 7 values differ from paired day 0 values, $P<0.005,{ }^{b}$ differs from ${ }^{a}, P<0.05$. Analyses by Student's two-tailed paired $t$ test. All other comparisons not significant at $P=0.05$ level.

* Negligible basophils in cultures of spleen alone at all concentrations.

periment to experiment (animal to animal); however, relative responses (with $\mathrm{OA}$ relative to absence of $\mathrm{OA}$ ) were consistent at each spleen cell dose for all experiments. A dose-response relationship existed between spleen cells added and basophils at $7 \mathrm{~d}$. Spleen cells, cultured alone with or without OA, contained very few basophils at $7 \mathrm{~d}$ throughout the dose ranges used (Table IIIA). Marrow cells cultured alone again

TABLE IIIB

Effect of Antigen and Added Autologous Spleen Cells on Basophil Production from Guinea Pig Marrow in 7-d Liquid Co-cultures

\begin{tabular}{crrc}
\hline & \multicolumn{2}{c}{ Basophils } & \\
\cline { 2 - 3 } Spleen cells added* & Without OA & With OA & Significancet \\
\hline$\times 10^{6} / \mathrm{cm}^{3}$ & \multicolumn{2}{c}{$\times 10^{3} / \mathrm{cm}^{3}$} & \\
None & $8.5 \pm 3.5$ & $13.4 \pm 3.5$ & NS \\
0.10 & $11.8 \pm 3.8$ & $16.5 \pm 4.4$ & NS \\
0.50 & $16.2 \pm 5.2$ & $32.4 \pm 9.5$ & $P<0.01$ \\
1.0 & $21.1 \pm 6.4$ & $52.0 \pm 13.0$ & $P<0.02$ \\
2.5 & $21.9 \pm 6.0$ & $44.0 \pm 13.4$ & $P<0.05$ \\
\hline
\end{tabular}

Results of five experiments, mean $\pm S E$.

* $0.5 \times 10^{6}$ autologous marrow cells used at each spleen cell dose (see text).

† "With OA" compared to "without OA", paired two-tailed $t$ test.

NS, not significant at $P=0.05$ level. 
showed a slight increase in basophils in the presence of OA (Tables IIIA and B).

CM effects on normal marrow basophil production. The effects of splenic cell CM prepared from OAtreated animals on normal guinea pig marrow cells in liquid culture are shown in Fig. 1. Significantly enhanced basophil and histamine production was shown on day 7 for marrow cultures in the presence of PHA- or OA-stimulated spleen CM from OA-treated animals (CM-PHA, CM-OA) when compared with control marrow cultures incubated without stimulus, or with PHA or OA alone. Further controls, including CM prepared from unstimulated or HSA- or RSAstimulated spleens of OA-treated animals, or CM from unstimulated normal spleen, demonstrated significantly less basophil-stimulating activity (calculated as BSI) when compared with CM-OA (Table IVA). CM from PHA- or PWM-stimulated spleens of normal or OA-treated animals all demonstrated higher BSI values than unstimulated splenic CM (Table IVB).

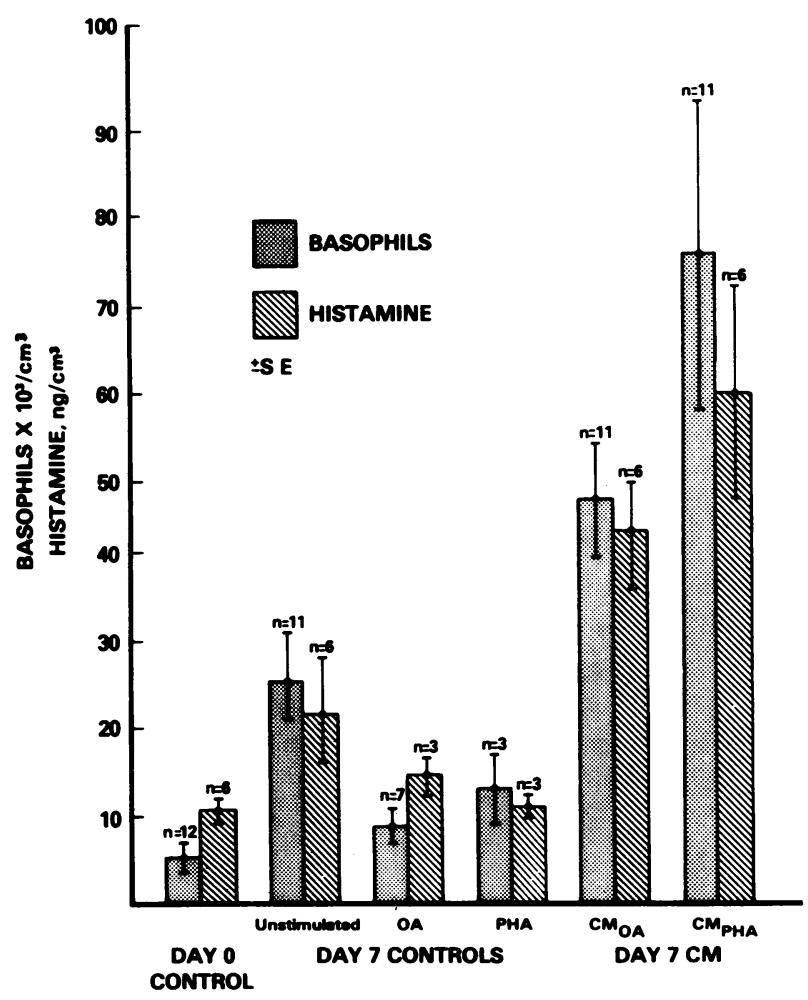

FIGURE 1 Results of seven experiments done in duplicate. Mean basophil counts and histamine values are expressed per cubic centimeter of liquid culture, $\pm S E$. Analysis was performed using the Student's paired $t$ test for multiple comparisons. Day 7 CM (CM-OA and CM-PHA) values are significantly different from day 0 controls and day 7 controls (unstimulated, OA, or PHA), $P<0.02$. Day 7 unstimulated control value differs from day 0 control for basophils only, $P<0.05$. There are no significant differences between other subgroups.
TABLE IVA

Basophil Stimulation Index* of Guinea Pig Splenic CM from Normal or OA-treated Animals: Specific Effect of OA

\begin{tabular}{ccc}
\hline & \multicolumn{2}{c}{ Guinea pig splenic source of CM } \\
\cline { 2 - 3 } Stimulus in vitro & Normal & OA-treated \\
\hline None & $1.8 \pm 0.4$ & $2.1 \pm 0.2$ \\
OA & $1.8 \pm 0.3$ & $3.5 \pm 0.5 \ddagger$ \\
HSA & NA $\oint$ & $2.3 \pm 0.5$ \\
RSA & $1.3 \pm 0.1$ & $1.3 \pm 0.4$ \\
\hline
\end{tabular}

* Ratio to control cultures without CM (see text). Day 7 results, 13 experiments.

$\ddagger P<0.01$ compared with all other CM.

$\S$ Not applicable.

The dose response of basophils and histamine to volume of CM-PHA added to liquid culture of normal guinea pig bone marrow cells is shown in Fig. 2A. Fig. 2B shows that the ratio of basophils on day 7 of CM-PHA-stimulated cultures to unstimulated cultures rises above unity even at $1 \% \mathrm{vol} / \mathrm{vol} \mathrm{CM}-\mathrm{PHA}$ added, and reaches a mean $>10$-fold increase at $20 \%$ $\mathrm{vol} / \mathrm{vol}$. These results were obtained with four separate CM-PHA batches, all of which demonstrated the same effect.

Splenic cell CSA, as measured by CFU-C production in 7-d methylcellulose cultures of separated guinea pig bone marrow cells, is shown in Fig. 3 and Table V. CM-OA and CM-PHA batches appeared to have linear plating efficiency and a dose-response relationship of CFU-C to volume of CM used (using three concentrations of $\mathrm{CM}$ ). Under the same conditions of preparation, CM derived from normal spleens were less active than spleen cell suspensions from OA-treated animals. CM-OA and CM-PHA were most active, in terms of assayable CSA, of the various CM tested in 10 experiments (Table V).

When parallel 7-d liquid suspension cultures of CSA-

TABLE IVB

Basophil Stimulation Index* of Guinea Pig Splenic CM from Normal or OA-treated Animals: Nonspecific Effect of Mitogen

\begin{tabular}{cll}
\hline & \multicolumn{2}{c}{ Guinea pig splenic source of $\mathrm{CM}$} \\
\cline { 2 - 3 } Stimulus in vitro & \multicolumn{1}{c}{ Normal } & OA-treated \\
\hline None & $1.8 \pm 0.4$ & $2.1 \pm 0.2$ \\
PHA & $3.6 \pm 0.6 \ddagger$ & $5.3 \pm 0.8 \S$ \\
PWM & $6.8 \pm 1.5 \ddagger$ & $7.3 \pm 1.5 \ddagger$ \\
\hline
\end{tabular}

* Ratio to control cultures without CM (see text). Day 7 results, 13 experiments.

$\$ P<0.05$ compared with unstimulated $\mathrm{CM}$.

$\S P<0.001$ compared with unstimulated CM. 

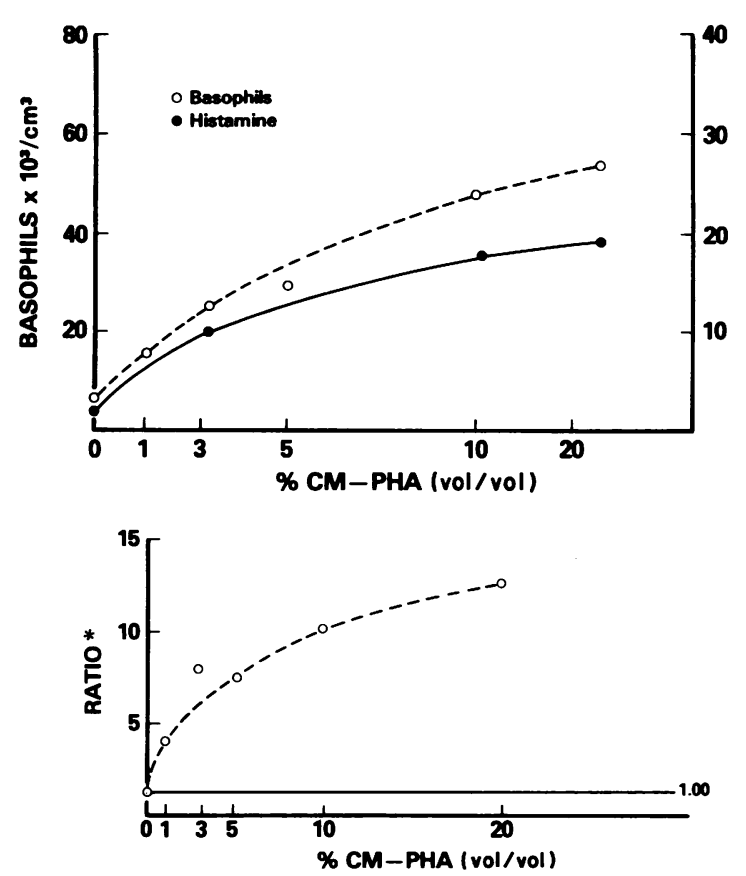

Figure 2 (A) Basophil and histamine response to CM-PHA in guinea pig bone marrow cultures. (B) Dose response of basophils to volume of PHA-CM from guinea pig spleen in liquid bone marrow cultures. Results of three experiments testing four different CM-PHA batches. Mean absolute basophil or histamine values, as indicated. Values at $1 \% \mathrm{vol} / \mathrm{vol}$ CM-PHA are significantly greater than starting values, $P$ $<0.01$ (Student's unpaired $t$ test). ${ }^{*}$, ratio to day 7 control values.

containing $\mathrm{CM}$ batches were assayed for basophil stimulation, BSI values in general correlated well over the entire assay ranges with $\mathrm{CSA}(r=+0.74, P<0.001)$.

Morphological examination of guinea pig CFU-C was revealing: in 50 colonies examined from a total of three experiments, only neutrophils or macrophages were seen in CM-PHA methylcellulose cultures. However, morphology of parallel liquid suspension cultures stimulated with CM-PHA revealed a wide range of cellular types, including basophils and eosinophils.

Prominent in stimulated liquid cultures were early promyelocytic-myelocytic basophils with palisading of basophilic granules around a prominent Golgi zone, nucleoli, and occasional mitotic figures. Further stages of basophil maturation were apparent in cells harvested on later days of culture.

The effect of CM-PHA on myeloid differentiation in liquid cultures is shown in Table VI. In unstimulated cultures, an increase in basophilic cells was found over the 7-d period, whereas total neutrophilic or eosinophilic cells did not change significantly. A further increase of morphologically recognizable basophils was seen in CM-PHA stimulated liquid cultures, so that a total mean 15 -fold increase ( $P$ $<0.001$ ) in basophils could be demonstrated by day 7 .
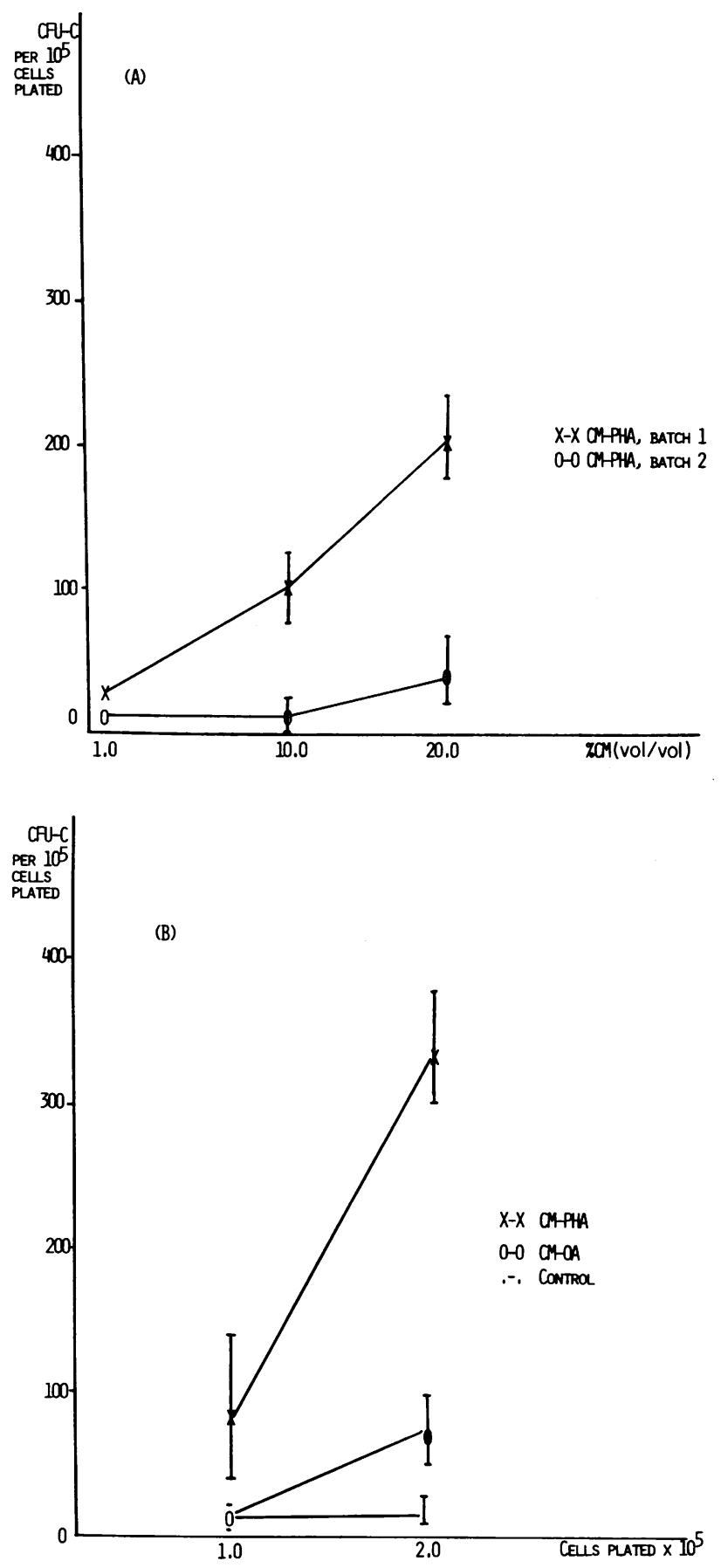

Figure 3 Plating efficiency and dose-response relationships of CFU-C to guinea pig splenic CM. Results of five experiments in duplicate, CFU-C $\pm S E$. (A) CM-PHA values differ from controls, $P<0.01$ : (B) CM-PHA significantly greater than CM-OA, $P<0.01$ : CM-OA significantly greater than control, $P<0.01$. All analyses by Student's $t$ test (two-tailed).

Histamine assays and correlation with basophils in vitro. Fig. 1 demonstrates the cell-associated histamine assay values as well as the basophil counts for the 
TABLE V

CSA* of Guinea Pig Splenic CM

\begin{tabular}{lcc}
\hline & \multicolumn{2}{c}{ Guinea pig spleen cell source of $\mathrm{CM}$} \\
\cline { 2 - 3 } Stimulus in vitro & Normal & OA-treated \\
\hline- & $17.0 \pm 16.0$ & $25.8 \pm 21.1$ \\
OA & $8.3 \pm 5.6$ & $59.8 \pm 18.0 \neq$ \\
PHA & $19.1 \pm 15.6$ & $226 \pm 40.2 \S$ \\
Control (no CM) & \multicolumn{2}{c}{$6.2 \pm 2.8$} \\
\hline
\end{tabular}

$*$ CFU-C $/ 10^{5}$ cells plated \pm SE. Day 7 results, 10 experiments. $\$ P<0.01$ compared with control, unstimulated OA-treated, and normal $\mathrm{CM}$ or OA-stimulated normal $\mathrm{CM}$.

$\S P<0.001$ compared with control and all other CM.

CM-stimulated marrow cultures. Histamine values were significantly increased in marrow cultures incubated with CM-PHA and CM-OA when compared with all other controls. The degree of correlation overall in these and other experiments between basophils and histamine was high $(r=+0.87)$; calculated histamine

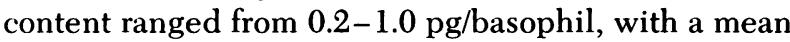
of $\sim 0.4 \mathrm{pg} / \mathrm{basophil}$. Histamine values of spleen cells cultured alone were low to negligible and never rose after $7 \mathrm{~d}$ of culture (data not shown).

Separated spleen CM effects on normal marrow basophil production. CM from separated splenic cells were assessed for activity in stimulating basophil production from normal guinea pig bone marrow cells in liquid cultures (Table VII). Prior T cell-depletion removed basophil-stimulating activity from splenic CM-PHA in three separate experiments. T cell-enriched splenic CM-PHA had as much or slightly greater basophil-stimulating activity than unfractionated spleen cell CM-PHA. In general, E-positive cells constituted $30-40 \%$ of unfractionated spleen cells, and $60-70 \%$

TABLE VI

Effect of CM-PHA on Differential Myeloid Cell

Counts in Normal Guinea Pig Bone Marrow Cultures

\begin{tabular}{lccc}
\hline & \multicolumn{3}{c}{ Day of culture } \\
\cline { 2 - 4 } & & \multicolumn{2}{c}{7} \\
\cline { 2 - 4 } Morphology & 0 & \multicolumn{1}{c}{ CM-* } & CM+1 \\
\hline Neutrophilic & $578 \pm 66.0$ & $588 \pm 96.6$ & $582 \pm 45.8$ \\
Eosinophilic & $61.3 \pm 19.9$ & $39.5 \pm 8.8$ & $86.3 \pm 21.5$ \\
Basophilic $\$$ & $5.83 \pm 1.1(a)$ & $25.7 \pm 5.5(b)$ & $75.8 \pm 17.8(c)$
\end{tabular}

Mean absolute cell counts $\pm \mathrm{SE} \times 10^{3} / \mathrm{cm}^{3}$. Results of seven experiments.

* CM-, without CM-PHA.

$\ddagger \mathrm{CM}+$, with CM-PHA.

$\$ b>a, P<0.05 ; c>a, P<0.001 ; c>b, P<0.05$. All other comparisons not significant at $P=0.05$ level.
TABLE VII

Effect of CM-PHA from Separated Splenic Cells of OA-treated Guinea Pigs on Basophils in Liquid Bone Marrow Cultures

\begin{tabular}{ll}
\hline Splenic CM source* & Basophils $\times 10^{3} / \mathrm{cm}^{3}$ \\
\hline Unfractionated & $41.0 \pm 8.3 \ddagger$ \\
T cell-depleted $\S$ & $18.8 \pm 5.2$ \\
T cell-enriched" & $54.7 \pm 10.0 \ddagger$ \\
Control (no CM) & $20.3 \pm 6.5$ \\
\hline
\end{tabular}

Day 7 values, \pm SE. Three experiments, in duplicate.

* CM-PHA, used at $20 \% \mathrm{vol} / \mathrm{vol}$.

$\ddagger P<0.01$ compared with control, unpaired two-tailed $t$ test. $\$ 85-95 \%$ of these cells were found to be surface immunoglobulin-positive after incubation with goat anti-guinea pig IgG (see text).

"60-70\% of these cells were found to be E-positive by ability to form rosettes with rabbit erythrocytes (see text).

of T-enriched fractions. Surface immunoglobulin positivity was found in $85-95 \%$ of interface (T-depleted) cells, $15-20 \%$ of T-enriched fractions, and $20-55 \%$ of unfractionated spleen cells. Histamine values correlated well with basophil counts in these experiments, with unfractionated spleen and T cell-enriched CMPHA causing statistically significant increases in 7-d histamine in vitro, when compared with $\mathrm{T}$ cell-depleted or control conditions $(P<0.01$, data not shown).

Characterization of basophil-stimulating activity CM-PHA. Table VIII shows that basophil-stimulating activity as well as CSA, derived from an active CMPHA, is predominantly heat stable and nondialyzable, although some basophil-stimulating activity appears to be diminished by these procedures. Further characterization and separation of these activities in CM-PHA is now in progress, and will be reported separately.

TABLE VIII

Colony- and Basophil-Stimulating Activities in Guinea Pig Splenic CM-PHA*

\begin{tabular}{lcc}
\hline \multicolumn{1}{c}{ Treatment } & Basophils $\times 10^{3} / \mathrm{cm}^{3}$ & CFU-C $/ 2 \times 10^{5}$ cells \\
\hline None & 49,50 & 478 \\
$56^{\circ} \mathrm{C}, 30 \mathrm{~min}$ & 37,38 & 477 \\
Dialyzed $\ddagger$ & 26,22 & 463 \\
Dialysate & 9,5 & 0 \\
Control & 9 & 0
\end{tabular}

One experiment, in duplicate.

* CM-PHA, PHA-stimulated spleen cell conditioned medium from OA-treated animal.

‡ Dialysis performed against phosphate-buffered saline for $24 \mathrm{~h}$, followed by dialysis against supplemented McCoy's 5A medium (see text) for $24 \mathrm{~h}$. 


\section{DISCUSSION}

A model of guinea pig basophil production in vitro has been established that implicates a direct role for antigen (OA), and soluble factors from splenic $\mathrm{T}$ lymphocytes in acting to promote the differentiation of bone marrow basophil precursors. The peripheral blood and bone marrow basophil responses seen in OA-treated guinea pigs are in accordance with protocols published by Dvorak et al. (20) for producing large populations of guinea pig basophils. In the current experiments, however, the maximal peripheral blood and marrow basophilia achieved was less than that originally reported by Winqvist (28), who used large doses of intraperitoneal heterologous plasma injections to promote basophilia; using a single protein, our values show a mean maximal rise of fivefold over a 3-5-d period of intraperitoneal OA injections. This discrepancy could be primarily the result of differences in the type or intensity of stimuli used, although differences in animal strains or animal age variables may also invalidate any comparison between our data and those of Winqvist. The peak basophil response observed occurred very early, i.e., by day 3 of injections. This suggests that release of already mature basophils from the marrow or other storage compartments may occur as a primary event in vivo, followed by further differentiation from a marrow precursor pool later on, in accord with observations on early, antigen-stimulated eosinophilia and assessments of changes in storage pool eosinophil numbers under various conditions (29). Total leukocyte counts were not different in OA-treated animals from saline-treated or untreated controls, indicating that absolute basophilia was stimulated by OA treatment.

In these studies, we have not examined the effects of acute phase (i.e., during OA treatment) serum on basophil production in vivo or in vitro. However, in some early experiments, draining (mediastinal) lymph node cells co-cultured with autologous marrow taken from OA-treated animals during the acute phase $(1 \mathrm{~d}$ after injections) augmented basophil production over the first $24-48 \mathrm{~h}$ in vitro when compared with marrow cells cultured without added lymph node cells (unpublished data). This suggested that the active participation of immune cells responding to $\mathrm{OA}$ stimulation was required for the development of in vivo basophilia, analogous to the requirements for $T$ lymphocytes in antigen-induced eosinophilia (13-17). Inasmuch as enhancement of basophil production in these early, "primary" lymph-node bone-marrow co-cultures was slight, presumably because the marrow precursor pool had already undergone near-maximal differentiation, we decided to pursue the interrelationships of antigen, immunocompetent cells, and bone marrow through the use of our secondary marrow-spleen co-cultures and subsequent $\mathrm{CM}$ experiments.
Bone marrow basophilia in vivo was followed serially in six animals and was found to have subsided totally by $60 \mathrm{~d}$ after intraperitoneal administration of $\mathrm{OA}$ (Table II). Autologous marrow and spleen cells from these animals were then shown to interact to produce a secondary basophil response in vitro in the presence of OA (Tables IIIA and B). This suggests that a splenic cell stimulates bone marrow basophil differentiation in vitro in the presence of specific antigen, because: (a) a significant increase in basophils was observed over $7 \mathrm{~d}$ of marrow-spleen co-culture when $\mathrm{OA}$ was added to the culture medium as opposed to unstimulated or control (HSA, RSA) co-cultures; (b) marrow cells incubated alone were not significantly stimulated (Tables IIIA and B) to produce basophils by the presence of OA in culture; $(c)$ spleen cells cultured alone with or without OA did not differentiate to basophils; and (d) morphologic evidence for basophil differentiation was obtained in these co-cultures. To further support this, a dose-response relationship between spleen cells added to a fixed marrow cell number and basophils in 7-d liquid cultures was demonstrated (Table IIIB). Basophil production was significantly enhanced by $\mathrm{OA}$ at spleen cell concentrations above $0.10 \times 10^{6} / \mathrm{cm}^{3}$ and appeared to plateau at high concentrations.

The enhancement by $\mathrm{OA}$ of basophil production in marrow-spleen co-cultures is compatible with an antigen-specific effect because control proteins (HSA or RSA) had no effect in these experiments. Antigen specificity is supported also by the finding of OA-enhanced basophil production in the $\mathrm{CM}$ experiments: OA-stimulated "immune" spleen produced CM capable of basophil production from normal marrow, whereas OA-stimulated "non-immune" spleen or HSA- or RSAstimulated immune spleen produced lower basophilstimulating activities (Table IVA). Using a formal antigen-crossover study to assess in vivo and in vitro basophilopoiesis in the guinea pig, we hope to confirm these findings.

The nature of the splenic basophilopoiesis-"helper" cell and its basophil-stimulating activity was examined in our $\mathrm{CM}$ experiments, using normal guinea pig marrow target cells. CM-OA and CM-PHA (both derived from spleen cells of OA-treated animals) significantly enhanced basophil and histamine production in a dose dependent fashion in these studies (Figs. 1 and 2). Furthermore, when splenic cells were separated by their ability to form E-rosettes with rabbit erythrocytes, a marker of guinea pig T lymphocytes (26), CM-PHA from $T$ cell-enriched, but not from $T$ cell-depleted suspensions, enhanced basophil production in vitro (Table VI). This supports the concept of a direct role of splenic $\mathrm{T}$ cells in basophilopoiesis.

Histamine content per liquid culture rose in good correlation with absolute basophil counts (Fig. 1). Galli et al. (30) have demonstrated newly synthesized hista- 
mine in 72-h cultures of mature, partially purified guinea pig basophils. The differences in histamine content over 7-d cultures demonstrated by us were several orders of magnitude higher than those demonstrated by Galli et al., with up to $35-40 \mathrm{ng} / \mathrm{cm}^{3}$ changes from day 0 to day 7 of culture. We must point out, however, that our culture assays measured preformed as well as newly synthesized histamine, although the large changes we have shown are indeed consistent with a major de novo differentiation of histamine-synthesizing cells. These data thus support the contention of growth of subpopulation of marrow precursor cells to a histamine-synthesizing cell type under conditions of antigen and T-cell product stimulation.

The basophil-stimulating activity described appears to be dependent on $(a) \mathrm{OA},(b)$ mitogen (PHA or PWM), and/or $(c)$ previous in vivo $O A$ treatment for its elaboration into splenic cell culture supernates. However, although the effect of OA appears to be specific (Table IVA), mitogen (PHA or PWM)-CM enhancement of basophilopoiesis is nonspecific: PHA- or PWM-stimulated normal and immune spleen CM both contained increased basophil-stimulating activity compared with unstimulated controls (Table IVB). Whether or not antigenic and mitogenic enhancement of basophilstimulating activity occurs through similar mechanisms is not clear from these studies; however, it is recognized that both PHA and PWM can nonspecifically stimulate production of CSA in both human and murine systems $(1,2,4-6,9,10)$. Likewise, an antigen-specific stimulation of neutrophil and eosinophil differentiation has been previously reported (3), but there is little information comparing the mechanisms of production of specific vs. nonspecific hematopoietic activities.

In our system in the guinea pig, nonimmune splenic CM had less colony- and basophil-stimulating activity, in general, than immune $\mathrm{CM}$, the most active batches being present in CM-PHA and CM-PWM. Furthermore, CM-OA and CM-PHA contain soluble factors capable of stimulating CFU-C in methylcellulose as well as basophil/histamine increases in liquid suspension cultures. The data further demonstrates that a good correlation exists between colony- and basophil-stimulating activities in most $\mathrm{CM}$ batches tested (Tables IV and $\mathrm{V}$ ). Whether or not the soluble splenic factor shown to stimulate basophil production in these experiments is a specific signal to basophilopoiesis or a complex of several different signals remains to be elucidated.

By morphological criteria in our CM experiments, basophils were the only myeloid cell type to demonstrate a statistically significant specific increase over a 7-d culture period when CM-PHA-stimulated cultures were compared with unstimulated cultures (Table VI). The linear dose response of both basophils and histamine to the volume of CM-PHA in liquid cultures is also consistent with a specific basophil-stimulating factor. This suggests the existence in these CM of a "basophilopoietin," a possibility further supported by preliminary Sephadex (Pharmacia Fine Chemicals) column fractionation data: CSA appears heterogeneous, whereas basophil-stimulating activity is maximal in the fractions eluting with albumin $(40,000-50,000 \mathrm{~mol}$ wt; unpublished data). The finding that semisolid CFU-C growth could also be enhanced by both CM-OA and CM-PHA (Table IV) points to a more generalized stimulation of hematopoietic elements by these CM, but does not exclude ultimate separability of basophil- from colony-stimulating activities. In this regard, work done by Burgess et al. (11) on eosinophil CSA has demonstrated this factor only in complex with other noneosinophil CSA from PWM-stimulated spleen cell supernates.

As far as we know, no basophil colonies in semisolid media have ever been reported; although this may be a reflection of the rarity of this cell line, another possibility is that basophil production is in some way curtailed or precluded in semisolid systems. Because basophils comprised $5-20 \%$ of all cells remaining in our stimulated liquid cultures at $7 \mathrm{~d}$, and because morphological observations on our methylcellulose colonies have failed to reveal recognizable basophils, it could be that the CFU-C stimulation in methylcellulose reflects the presence of only granulocyte-macrophagestimulating factors from the CM tested. Ruscetti et al. (31) have shown that CSA from murine splenic CM is functionally separable from the lymphokine migration inhibition factor. Although certain biological activities definable in CM prepared from lymphocytes are varied, some molecules may actually have convergent functions. Further attempts at characterization and separation of guinea pig splenic CM activities, as well as differential analysis of their potential cellular courses and targets, are now being pursued.

The data presented here support the contention that immunocompetent cells secrete factors capable of stimulating specialized hematopoietic cell differentiation. Our findings demonstrate OA-specific basophil production in vitro as well as basophilopoiesis in response to soluble factors derived from guinea pig splenic $T$ lymphocytes. This model is now being used to further characterize the ontogeny of the basophil and its cellular and subcellular regulation.

Note added in proof. Nicola et al. have recently reported (Blood. 54: 614-627) the separation of granulocytemacrophage CSA from eosinophil CSA. This is a direct extension of the work quoted by Burgess et al. (11).

\section{ACKNOWLEDGMENTS}

We wish to thank Ms. Phyllis Gendron for her work in preparing the manuscript and Sharon Behman for her help with the histamine assays. 


\section{REFERENCES}

1. Cline, M. J., and D. W. Golde. 1974. Production of colonystimulating activity by human lymphocytes. Nature (Lond.). 248: 703.

2. Ruscetti, F. W., and P. A. Chervenick. 1975. Release of colony-stimulating activity from thymus-derived lymphocytes. J. Clin. Invest. 55: 520-527.

3. Ruscetti, F. W., R. H. Cypess, and P. A. Chervenick. 1976. Specific release of neutrophilic- and eosinophilic-stimulating factors from sensitized lymphocytes. Blood. 47: 757-765.

4. Metcalf, D., H. R. MacDonald, N. Odartchenko, and B. Sordat. 1975. Growth of mouse megakaryocyte colonies in vitro. Proc. Natl. Acad. Sci. (U. S. A.). 72: 1744-1748.

5. Morgan, D. A., F. W. Ruscetti, and R. Gallo. 1976. Selective in vitro growth of T-lymphocytes from normal human bone marrows. Science (Wash. D. C.). 193: 1007-1008.

6. Shah, R. G., L. H. Caporale, and M. A. S. Moore. 1977. Characterization of colony-stimulating activity produced by human monocytes and phytohemagglutinin-stimulated lymphocytes. Blood. 50: 811-821.

7. Nathan, D., L. Chess, D. G. Hillman, B. Clarke, J. Breard, E. Merler, and D. E. Housman. 1978. Human erythroid burst-forming unit: T-cell requirement for proliferation in vitro. J. Exp. Med. 147: 324-339.

8. Miyoshi, I., H. Uchida, T. Tsubota, I. Kubouishi, S. Hiraki, and K. Kitajima. 1977. Basophilic differentiation of chronic myelogenous leukemia cells in vitro. Scand. J. Hematol. 19: 321-326.

9. Dao, C., D. Metcalf, and G. Bilski-Pasquier. 1977. Eosinophil and neutrophil colony forming cells in culture. Blood. 50: 833-839.

10. Dresch, C., G. R. Johnson, and D. Metcalf. 1977. Eosinophil colony formation in semisolid cultures of human bone marrow cells. Blood. 49: 835-844.

11. Burgess, A. W., D. Metcalf, and S. Russel. 1977. Regulation of hematopoietic differentiation and proliferation by colony-stimulating factors. Cold Spring Harbor Symposium on Differentiation of Normal and Neoplastic Hematopoietic Cells. 6-11 September. Abstract. 21.

12. Barker, B. E., P. Farnes, and P. E. Harrison. 1976. In vitro differentiation of basophil granulocytes from human blood CFU-C. J. Cell Biol. 70: 100a. (Abstr.)

13. Basten, A., and P. B. Beeson. 1970. Mechanism of eosinophilia. II. Role of the lymphocyte. J. Exp. Med. 131: 1288-1305.

14. Colley, D. G. 1976. Eosinophils and immune mechanisms. IV. Culture conditions, antigen requirements, production kinetics and immunologic specificity of the lymphokine eosinophil stimulation promoter. Cell. Immunol. 24: 328-335.

15. Greene, B. M., and D. G. Colley. 1976. Eosinophils and immune mechanisms. III. Production of the lymphokine eosinophil stimulation promoter by mouse $\mathrm{T}$ lymphocytes. J. Immunol. 116: 1078-1083.

16. Miller, A. M., and M. P. McGarry. 1976. A diffusible stimulator of eosinophilopoiesis produced by lymphoid cells as demonstrated with diffusion chambers. Blood. 48: 293-300.
17. Weller, P. F., J. A. Dvorak, and W. C. Whitehouse. 1978. Human eosinophil stimulating promoter lymphokine: production by antigen stimulated lymphocytes and assay with a new electro-optical technique. Cell. Immunol. 40: 91-102.

18. Parish, W. E., E. Luckhurst, and S. I. Cowan. 1977. Eosinophilia. V. Delayed hypersensitivity, blood and bone marrow eosinophilia, induced in normal guinea pigs by adoptive transfer of lymphocytes from syngeneic donors. Clin. Exp. Immunol. 29: 75-83.

19. Eccleston, E., B. J. Leonard, J. S. Lowe, and H. J. Welford. 1973. Basophilic leukemia in the albino rat and a demonstration of the basopoietin. Nat. New Biol. 244: 73-76.

20. Dvorak, H. F., S. S. Selvaggio, A. M. Dvorak, R. B. Colvin, D. B. Lean, and J. Rypsyc. 1974. Purification of basophilic leukocytes from guinea pig blood and bone marrow. $J$. Immunol. 113: 1694-1702.

21. Askenase, P. W. 1977. Role of basophils, mast cells and vasoamines in hypersensitivity reactions with a delayed time course. Prog. Allergy. 23: 199-320.

22. Day, R. P., D. P. Singal, and J. Bienenstock. 1976. Presence of thymic antigen on rabbit basophils. J. Immunol. 114: 1333-1336.

23. Schulte-Wissermann, H., M. S. Borzy, R. Albrecht, and R. Hong. 1979. Functional relationship of macrophages and basophils to the thymus gland. Scand. J. Immunol. 9: 45-52.

24. Shortman, K., N. Williams, and P. Adams. 1972. The separation of different cell classes from lymphoid organs. V. Simple procedures for the removal of cell debris, damaged cells and erythroid cells from lymphoid cell suspensions. J. Immunol. Methods. 1: 273-287.

25. Beaven, M. A., S. Jacobsen, and Z. Horakova. 1972. Modification of the enzymatic isotopic assay of histamine and its application to measurement of histamine in tissues, serum and urine. Clin. Chim. Acta. 37: 91-103.

26. Wilson, A. B., and B. W. Gurner. 1975. Increased affinity of guinea pig thymocytes and thymic-dependent lymphocytes for papain-treated rabbit erythrocytes compared to untreated erythrocytes. J. Immunol. Methods. 7: $163-168$.

27. Pearce, F. L., H. Behrendt, U. Blum, G. Poblete-Freundt, P. Pult, Ch. Stang-Voss, and W. Schmutzler. 1977. Isolation and study of functional mast cells from lung and mesentery of the guinea pig. Agents Actions. 7: 45-56.

28. Winqvist, G. 1960. Experimental production of basophil granulocytes in the guinea pig. Exp. Cell. Res. 19: 7-12.

29. Beeson, P. B., and D. A. Bass. 1977. In The Eosinophil, Major Problems in Internal Medicine. W. B. Saunders Company, Philadelphia. 14: 10-14.

30. Galli, S. J., A. S. Galli, A. M. Dvorak, and H. F. Dvorak. 1976. Metabolic studies of guinea pig basophilic leucocytes in short-term tissue culture. I. Measurement of histamine-synthesizing capacity by using an isotopic-thin layer chromatographic assay. J. Immunol. 117: 1085-1092.

31. Ruscetti, F. W., J. Allalunis, and P. A. Chervenick. 1978. Granulocyte colony stimulating activity from lymphocytes: separation from lymphokines by cytochalasin B. Cell. Immunol. 36: 388-392. 